\title{
Does fetal growth restriction influence body composition at school age?
}

\author{
Marilia C. Lima, ${ }^{1}$ Henrique F. Dantas, ${ }^{2}$ Rosemary J. M. Amorim, ${ }^{3}$ Pedro I. C. Lira ${ }^{4}$
}

\begin{abstract}
Objective: To assess the influence of low birth weight in full-term infants on body composition at school age.

Method: This is a cross-sectional study nested in a cohort of 375 infants recruited at birth between 1993 and 1994 in the state of Pernambuco, Brazil. At 8 years of age, the body composition of 213 children from this cohort was assessed by measurement of triceps and subscapular skinfold thickness and mid upper arm circumference. Multivariable linear regression analysis was used to identify the influence of low birth weight, socioeconomic condition, maternal nutritional status, and child morbidity on triceps skinfold thickness.

Results: Mean triceps and subscapular skinfold thickness, mid upper arm circumference, and upper arm muscle and fat areas were lower in children born at term with low weight than in those with appropriate birth weight. However, these differences were not statistically significant. Multivariable linear regression analysis showed that the relative majority of variance in triceps skinfold thickness $(12.3 \%)$ was explained by socioeconomic variables, particularly per capita family income $(9.1 \%)$, followed by anemia and past hospitalization (which, together, explained $5.6 \%$ of variance) and maternal body mass index, which contributed toward $2.4 \%$ of this variance. Low birth weight had no influence on triceps subcutaneous fat deposition in this age group.

Conclusion: Socioeconomic factors and a history of morbidity had a greater influence on body composition than low birth weight in schoolchildren born at term.

J Pediatr (Rio J). 2011;87(1):29-35: Low birth weight, fetal growth retardation, skinfold thickness, body composition, nutritional status, cohort studies.
\end{abstract}

\section{Introduction}

Fetal growth restriction is the foremost cause of low birth weight (LBW) in developing countries, and is a characteristic reflection of the pervasive social and economic inequalities of these regions. ${ }^{1}$ Studies have shown that fetal malnutrition is a predisposing factor for increased morbidity in the first year of life and higher hospitalization rates in economically underprivileged regions, particularly due to respiratory infections and diarrheal diseases, and consequent increases in child mortality. ${ }^{2,3}$

A relationship exists between infectious diseases and nutritional issues. Nutritional status compromise leads to a decline in resistance to infection, and infections, in turn, jeopardize nutritional status by producing negative effects on appetite and food acceptance, thus maintaining the

1. Doutora, Medicina. Professora adjunta, Departamento Materno Infantil, Universidade Federal de Pernambuco (UFPE), Recife, PE, Brazil.

2. Mestre, Saúde da Criança e do Adolescente. Professor assistente, Departamento Materno Infantil, UFPE, Recife, PE, Brazil.

3. Doutora, Nutrição. Professora adjunta, Departamento Materno Infantil, UFPE, Recife, PE, Brazil.

4. Doutor, Medicina. Professor associado, Departamento de Nutrição, UFPE, Recife, PE, Brazil.

No conflicts of interest declared concerning the publication of this article.

Financial support: The Wellcome Trust, UK (Grant No 064220Z/01Z).

Suggested citation: Lima MC, Dantas HF, Amorim RJ, Lira PI. Does fetal growth restriction influence body composition at school age? J Pediatr (Rio J). 2011;87(1):29-35.

Manuscript submitted Jul 23 2010, accepted for publication Oct 122010.

doi:10.2223/JPED.2053 
vicious circle of infectious disease and nutritional deficits. Micronutrient deficiencies, including iron deficiency, are frequently associated with decline in nutritional status and can induce poor host response to infection. 4,5

If health conditions in childhood are affected by the synergistic action of a biological risk (fetal growth restriction) and infectious diseases and poor nutritional status, in adulthood, a history of fetal malnutrition has been associated with various chronic conditions, such as obesity, type 2 diabetes, hypertension, dyslipidemia, and ischemic stroke. 6,7

Meas et al. ${ }^{8}$ found that adults who had been born full-term small for gestational age (SGA) gained a greater percentage of fat mass than those born appropriate for gestational age. These data suggest that the consequences of intrauterine growth restriction on body composition persist beyond the period of accelerated growth in early postnatal life.

There is a dearth of published studies assessing body composition at school age by means of body fat and lean mass percentages. In Northeast Brazil, a birth cohort has been followed since 1993, providing the opportunity to conduct the present study in this age range, in an attempt to determine the influence of LBW on body composition at 8 years of age in children born full-term, with low or appropriate birth weight (ABW), after adjusting for socioeconomic factors, maternal nutritional status, and past medical history.

\section{Methods}

The study was carried out in five municipalities of the southern Zona da Mata region of the state of Pernambuco (Água Preta, Catende, Joaquim Nabuco, Palmares, and Ribeirão), each located approximately $120 \mathrm{~km}$ from the state capital, Recife. This geographic area is traditionally characterized by sugarcane monoculture, which constitutes the livelihood of the majority of the economically active population in the region, thus contributing to underemployment or unemployment during the offseason.

This cross-sectional study was nested in a cohort of full-term infants (163 LBW, 212 ABW) that sought to follow growth and development over the first two years of life. Neonates were recruited in the first hours of life from six local maternity hospitals, between January 1993 and August 1994. The LBW group comprised infants weighing 1,500 to 2,499 $\mathrm{g}$ at delivery. The control group was constructed by pairing each LBW infant with the next baby of the same gender with an appropriate birth weight $(3,000-3,499 \mathrm{~g}) .^{3}$

Gestational age was assessed by a pediatrician using the method described by Capurro et al., ${ }^{9}$ and a series of anthropometric parameters were measured in the first 24 hours of life. ${ }^{3}$ Nutritional status at birth was assessed on the basis of birth weight and body proportionality, defined by a combination of the ponderal index (PI) and length-forage. PI was calculated with the Rohrer formula [PI = mass (g) / length $\left.(\mathrm{cm})^{3} \times 100\right]$. LBW infants were classified as stunted when length-for-age was $<-2 \mathrm{z}$ scores and the PI was $\geq 2.5$; wasted when length-for-age was $\geq-2 \mathrm{z}$ scores and the PI was < 2.5; and both stunted and wasted when length-for-age was $<-2 \mathrm{z}$ scores and the PI was $<2.5 .{ }^{10}$ As this latter group comprised only 17 children, it was pooled with the stunted group $(n=13)$ for analysis. Five children could not be classified into any of the three categories and were thus excluded from the sample.

Data collection at 8 years of age was carried out by a trained researcher between May 2001 and August 2002. At this time, a new interview was conducted, using a structured questionnaire to inquire as to family socioeconomic status and health of the child (morbidity and hospitalizations) over the previous year.

After the interview, body composition was assessed. Mid upper arm circumference was measured in triplicate with a non-stretch Lasso-o ${ }^{\circledR}$ circumference tape (Child Growth Foundation, London, UK). Skinfold thickness was also measured in triplicate with a Holtain skinfold caliper. In case measurements did not agree within $1 \mathrm{~mm}$, the extreme value was ignored and measurements were repeated. The arithmetic mean of the three measurements was used for data analysis. Maternal height and weight was also measured, and maternal BMI was calculated from the data obtained $\left[\right.$ BMI $=$ mass $(\mathrm{kg}) /$ height $\left.(\mathrm{m})^{2}\right] .^{10}$

Upper arm volume measurements were calculated on the basis of triceps skinfold (TSF) thickness and mid upper arm circumference (C), according to the formulae described by Frisancho ${ }^{11}$ : total upper arm area $=C^{2} /(4 \mathrm{x}$ $\pi)$; upper arm muscle area $\left.=\left[C-(\operatorname{TSF} \times \pi)^{2}\right] /(4 \times \pi)\right]$; upper arm fat area $=$ total upper arm area - upper arm muscle area; and arm fat index = (upper arm fat area / total arm area) $\times 100$.

Hemoglobin levels were measured with a portable photometer (HemoCue Ltd., Sheffield, UK), using capillary blood samples obtained by the fingerstick method. Children were considered anemic when hemoglobin levels were lower than $11.5 \mathrm{~g} / \mathrm{dL} .{ }^{12}$

All forms were pre-coded and were checked daily for data consistency. Double data entry was used and verified with the Epi-Info 6.04 software package (U.S. Centers for Disease Control and Prevention, Atlanta, GA). Statistical analyses were performed with the Statistical Package for the Social Sciences (SPSS) 12.0 for Windows (SPSS Inc., Chicago, IL). TSF thickness was chosen as the main response variable, as it is considered a good indirect estimate of body fat percentage in children, and was assessed as a continuous variable. ${ }^{13}$ Student's $t$ test and analysis of variance (ANOVA) were used for comparison of means and the chi-square test 
was used to compare differences in proportion in bivariate analysis. The significance level was set at $\leq 0.05$.

Multivariate linear regression analysis was performed to assess the individual impact of independent variables on TSF thickness, using a hierarchical model in which variables were entered in blocks. Of the explanatory variables, hemoglobin level was treated as a continuous variable and all others as dichotomous variables, except for body proportionality at birth, which was treated as a dummy. All variables with $p<0.20$ on bivariate analysis were selected for inclusion in the regression analysis model. The initial model thus included 10 socioeconomic variables (per capita family income, maternal educational attainment, family size, persons per room, paternal cohabitation, flooring material, availability of flush toilets, waste disposal, ownership of refrigerator and cassette player); the second block included two maternal variables (age and BMI); the third, body proportionality at birth; and the fourth, hospitalization during the year preceding the study and hemoglobin levels at 8 years of age. Variables with $p<0.20$ in each block were kept for final analysis.

The study was approved by the Centro de Ciências da Saúde da Universidade Federal de Pernambuco Research Ethics Committee and by the London School of Hygiene and Tropical Medicine Ethics Committee. Informed consent was provided by the guardians of all children included in the study sample.

\section{Results}

A total of 213 children were available for enrollment at 8 years of age: $86(40.4 \%)$ LBW and 127 (59.6\%) ABW - $56.8 \%$ of the original cohort. Of those lost to follow-up, $15.4 \%$ had died (17 children in the LBW group and eight in the ABW group); $26 \%$ had migrated; and $58.6 \%$ could not be located. Comparison of socioeconomic status at birth of children who completed the study and those lost to follow-up according to birth weight showed that, regardless of birth weight, the highest percentage of loss to follow-up occurred among children living in the worst socioeconomic conditions. ${ }^{14}$

Table 1 shows that anthropometric indicators of nutritional status (triceps and subscapular skinfold thickness, arm circumference, total upper arm area and upper arm muscle and fat area, and arm fat index) had lower mean values in full-term LBW infants, with no significant betweengroup differences, however.

Table 2 shows significant reductions in TSF in children whose families had lower income, lower levels of maternal education, greater numbers of people residing in the household, and poor sanitation and low ownership of domestic appliances.

Table 3 shows that mean TSF thickness values were lower in children born to mothers younger than 30 years and with a BMI below $25 \mathrm{~kg} / \mathrm{m}^{2}$ differences were only statistically significant for BMI, however. Analysis of body proportionality at birth showed that LBW infants had lower mean TSF thickness values than ABW infants, although the difference did not reach statistical significance. There were no gender-related between-group differences in mean TSF thickness. At 8 years of age, mean TSF thickness values were lower in children who had been hospitalized in the year preceding the study and in those with hemoglobin levels below $11.5 \mathrm{~g} / \mathrm{dL}$.

Regression analysis with TSF thickness as a dependent variable yielded the results shown in Table 4. In model 1 , only per capita family income and maternal educational attainment remained significant after adjustment for the remaining socioeconomic variables. Model 2 shows that maternal BMI remained significant after adjusting for socioeconomic variables and maternal age. Body proportionality at birth, despite a p-value $>0.20$, was kept in model 3 as a variable of interest for the study and a variable required for model adjustment. A similar result was obtained when birth weight was used instead of body proportionality in this model. In model 4 , the hemoglobin

Table 1 - Anthropometry at 8 years of age, according to birth weight

\begin{tabular}{|c|c|c|c|c|c|}
\hline \multirow[b]{2}{*}{ Nutritional status indicators } & \multicolumn{2}{|c|}{ LBW $(n=86)$} & \multicolumn{2}{|c|}{$A B W(n=127)$} & \multirow[b]{2}{*}{$\mathbf{p}$} \\
\hline & Mean & $95 \% \mathrm{CI}$ & Mean & $95 \% \mathrm{CI}$ & \\
\hline Triceps skinfold thickness (mm) & 9.05 & $8.2-9.9$ & 9.53 & $8.9-10.2$ & 0.37 \\
\hline Subscapular skinfold thickness (mm) & 6.70 & $6.0-7.4$ & 7.14 & $6.6-7.7$ & 0.34 \\
\hline Arm circumference $(\mathrm{cm})$ & 18.14 & $17.6-18.7$ & 18.69 & $18.3-19.1$ & 0.10 \\
\hline Total upper arm area $\left(\mathrm{cm}^{2}\right)$ & 26.62 & $24.9-28.3$ & 28.26 & 26.9-29.7 & 0.14 \\
\hline Upper arm muscle area $\left(\mathrm{cm}^{2}\right)$ & 18.77 & $18.0-19.6$ & 19.79 & $19.1-20.5$ & 0.06 \\
\hline Upper arm fat area $\left(\mathrm{cm}^{2}\right)$ & 7.86 & $6.8-8.9$ & 8.48 & $7.7-9.3$ & 0.34 \\
\hline Arm fat index (\%) & 28.02 & $26.5-29.5$ & 28.68 & $27.5-29.3$ & 0.49 \\
\hline
\end{tabular}

$95 \% \mathrm{Cl}=95 \%$ confidence interval; ABW = appropriate birth weight; LBW = low birth weight. 
Table 2 - Mean triceps skinfold thickness at 8 years of age, according to socioeconomic variables

\begin{tabular}{|c|c|c|c|c|c|}
\hline Socioeconomic variables & $\mathbf{n}$ & $\%$ & Mean & SD & $\mathbf{p}$ \\
\hline \multicolumn{6}{|l|}{ Per capita family income* } \\
\hline$<0.25$ & 74 & 34.7 & 8.09 & 2.78 & $<0.001$ \\
\hline$\geq 0.25$ & 139 & 65.3 & 10.00 & 4.08 & \\
\hline \multicolumn{6}{|c|}{ Maternal educational attainment (years of schooling) } \\
\hline $0-4$ & 96 & 45 & 8.28 & 2.60 & $<0.001$ \\
\hline$\geq 5$ & 117 & 55 & 10.20 & 4.36 & \\
\hline \multicolumn{6}{|l|}{ Family size } \\
\hline $5-14$ & 127 & 59.6 & 8.65 & 3.17 & 0.001 \\
\hline $2-4$ & 86 & 40.4 & 10.34 & 4.38 & \\
\hline \multicolumn{6}{|l|}{ Persons per room } \\
\hline$\geq 2$ & 36 & 16.9 & 8.06 & 2.05 & 0.03 \\
\hline$<2$ & 177 & 83.1 & 9.60 & 4.01 & \\
\hline \multicolumn{6}{|l|}{ Paternal cohabitation } \\
\hline No & 90 & 42.3 & 8.94 & 3.34 & 0.19 \\
\hline Yes & 123 & 57.7 & 9.63 & 4.02 & \\
\hline \multicolumn{6}{|l|}{ Flooring material } \\
\hline Other & 158 & 74.2 & 8.93 & 3.13 & 0.008 \\
\hline Ceramic tile & 55 & 25.8 & 10.50 & 5.11 & \\
\hline \multicolumn{6}{|l|}{ Plumbing } \\
\hline No flush toilet & 68 & 31.9 & 8.53 & 2.50 & 0.03 \\
\hline Flush toilet & 145 & 68.1 & 9.72 & 4.22 & \\
\hline \multicolumn{6}{|l|}{ Waste disposal } \\
\hline Other & 31 & 14.6 & 8.49 & 1.90 & 0.18 \\
\hline Direct collection & 182 & 85.4 & 9.48 & 4.01 & \\
\hline \multicolumn{6}{|l|}{ Refrigerator in household } \\
\hline No & 51 & 23.9 & 8.38 & 2.76 & 0.04 \\
\hline Yes & 162 & 76.1 & 9.63 & 4.02 & \\
\hline \multicolumn{6}{|l|}{ Cassette player in household } \\
\hline No & 58 & 27.2 & 8.44 & 3.05 & 0.04 \\
\hline Yes & 155 & 72.8 & 9.67 & 3.99 & \\
\hline
\end{tabular}

$\mathrm{SD}=$ standard deviation

* In minimum wages.

level and history of hospitalization variables maintained significance after adjustment for the remaining variables. Overall, independent variables accounted for $21.6 \%$ of variation in TSF thickness; the socioeconomic variables block explained much of this variation $(12.3 \%)$, with particular emphasis on per capita family income $(9.1 \%)$, followed by child morbidity-related variables (5.6\%).

\section{Discussion}

This study has several positive points in its favor. It is a cohort study that has at its disposal a database on the socioeconomic and environmental conditions of participating families, maternal reproductive history, gestational age, and weight and length at birth, and has taken a strict methodological stance to follow-up of the participating children. The main limitation of this study concerns the substantial loss to follow-up 8 years after enrollment. This is a common issue in cohort studies, particularly those carried out in developing countries. This study was conducted in a poor region of the state of Pernambuco, in Northeast Brazil, an area that features high unemployment rates and intense migration of local populations to the South and Southeast of the country in search of better living conditions. This is a major limitation; however, any possible selection bias will have had the effect of underestimating the negative effects of individuals in more disadvantaged socioeconomic conditions. ${ }^{14}$

Nutritional status at birth did not influence body composition at 8 years of age. Similar results were reported by Malina et al., ${ }^{15}$ who found that birth weight accounted for a small variation in subcutaneous fat at school age. Other studies, however, such as those by Hediger et al. ${ }^{16}$ and Hack et al., ${ }^{17}$ found that LBW infants had greater fat stores, and suggested that differences in body composition could be a link between fetal growth disorders and fat-associated diseases of adulthood. ${ }^{16,17}$ 
Table 3 - Mean triceps skinfold thickness at 8 years of age according to maternal and child variables

\begin{tabular}{|c|c|c|c|c|c|}
\hline Variable & $\mathbf{n}$ & $\%$ & Mean & SD & $\mathbf{p}$ \\
\hline \multicolumn{6}{|l|}{ Maternal } \\
\hline \multicolumn{6}{|l|}{ Age (years)* } \\
\hline $21-29$ & 90 & 49.7 & 8.91 & 3.15 & 0.10 \\
\hline $30-52$ & 91 & 50.3 & 9.88 & 4.59 & \\
\hline \multicolumn{6}{|l|}{ BMI $\left(\mathrm{kg} / \mathrm{m}^{2}\right)^{*}$} \\
\hline$<25$ & 90 & 49.7 & 8.75 & 3.33 & 0.02 \\
\hline$\geq 25$ & 91 & 50.3 & 10.05 & 4.42 & \\
\hline \multicolumn{6}{|l|}{ Child (at birth) } \\
\hline \multicolumn{6}{|l|}{ Body proportionality ${ }^{\dagger}$} \\
\hline Low birth weight, stunted & 30 & 14.4 & 8.82 & 2.67 & 0.62 \\
\hline Low birth weight, wasted & 51 & 24.5 & 9.18 & 4.65 & \\
\hline Appropriate birth weight & 127 & 61.1 & 9.53 & 3.71 & \\
\hline \multicolumn{6}{|l|}{ Gender } \\
\hline Male & 88 & 41.3 & 9.32 & 4.38 & 0.97 \\
\hline Female & 125 & 58.7 & 9.35 & 3.33 & \\
\hline \multicolumn{6}{|l|}{ Child (at 8 years of age) } \\
\hline \multicolumn{6}{|c|}{ Hospitalization in year preceding study } \\
\hline Yes & 24 & 11.3 & 7.53 & 1.69 & 0.01 \\
\hline No & 129 & 88.7 & 9.57 & 3.92 & \\
\hline \multicolumn{6}{|l|}{ Hemoglobin $(\mathrm{g} / \mathrm{dL})$} \\
\hline$<11.5$ & 36 & 16.9 & 7.81 & 2.00 & 0.008 \\
\hline$\geq 11.5$ & 177 & 83.1 & 9.65 & 4.00 & \\
\hline
\end{tabular}

$\mathrm{BMI}=$ body mass index; $\mathrm{SD}=$ standard deviation .

* Missing data for 32 cases.

$\dagger$ Unclassifiable in 5 cases.

Table 4 - Linear regression of factors associated with TSF thickness in children at 8 years of age

\begin{tabular}{|c|c|c|c|c|c|}
\hline Variable & Unadjusted $\beta$ & $95 \% \mathrm{CI}$ & Adjusted $\boldsymbol{\beta}$ & $95 \% \mathrm{CI}$ & $\mathbf{R}^{2}(\%)$ \\
\hline \multicolumn{6}{|l|}{ Model $1 *$} \\
\hline Per capita family income ${ }^{\dagger}<0.25 \mathrm{MWs}$ & $-1.92^{\ddagger}$ & $-2.96:-0.87$ & $-2.02^{\S}$ & $-3.26:-0.78$ & $9.1(9.1)$ \\
\hline Maternal education ${ }^{+} 0-4$ years of schooling & $-1.91^{\ddagger}$ & $-2.91:-0.92$ & $-1.52 \|$ & $-2.71:-0.32$ & $3.2(12.3)$ \\
\hline \multicolumn{6}{|l|}{ Model 2} \\
\hline Maternal $\mathrm{BMI}^{\dagger}<25 \mathrm{~kg} / \mathrm{m}^{2}$ & $-1.30 \|$ & $-2.45:-0.15$ & $-1.11^{\|}$ & $-2.23:-0.01$ & $2.4(14.7)$ \\
\hline Maternal age ${ }^{\dagger} 21-29$ years & -0.97 & $-2.13: 0.19$ & -0.80 & $-1.94: 0.33$ & $1.0(15.7)$ \\
\hline \multicolumn{6}{|l|}{ Model 3} \\
\hline LBW, stunted $^{+}$ & -0.61 & $-2.10: 0.88$ & 0.03 & $-1.73: 1.79$ & $0.0(15.7)$ \\
\hline LBW, wasted $^{+}$ & -0.21 & $-1.43: 1.01$ & 0.51 & $-0.87: 1.90$ & $0.3(16.0)$ \\
\hline \multicolumn{6}{|l|}{ Model 4} \\
\hline Hemoglobin $^{+}<11.5 \mathrm{~g} / \mathrm{dL}$ & $-1.84 \S$ & $-3.18:-0.49$ & $-1.70 \|$ & $-3.16:-0.25$ & $2.5(18.5)$ \\
\hline History of hospitalization ${ }^{+}$ & $-2.04 \|$ & $-3.64:-0.44$ & $-2.39 \|$ & $-4.24:-0.55$ & $3.1(21.6)$ \\
\hline
\end{tabular}

$95 \% \mathrm{Cl}=95 \%$ confidence interval; $\beta=$ unstandardized regression coefficient; $\mathrm{BMI}=$ body mass index; $\mathrm{LBW}=$ low birth weight; $\mathrm{MW}$ = minimum wages; $\mathrm{R}^{2}=\mathrm{coefficient}$ of determination; TSF = triceps skinfold.

* Model 1: adjusted for family size, persons per room, paternal cohabitation, flooring material, availability of flush toilets, waste disposal, and refrigerator and cassette player ownership.

+ Reference categories for categorical variables: per capita family income $\geq 0.25 \mathrm{MWs}$; maternal education $\geq 5$ years of schooling; maternal BMI $\geq 25 \mathrm{~kg} / \mathrm{m}^{2}$; maternal age > 29 years; LBW, stunted: wasted LBW and appropriate birth weight; LBW, wasted: stunted LBW and appropriate birth weight; hemoglobin levels $\geq 11.5 \mathrm{~g} / \mathrm{dL}$; no history of hospitalization.

$\neq \mathrm{p} \leq 0.001$.

$\S p<0.01$.

$\| \mathrm{p} \leq 0.05$. 
TSF thickness varies according to gender and age; it increases progressively, particularly in females. ${ }^{18,19}$ One hypothesis that may arise from this study is that school age may not be the most appropriate time to prove an association between LBW and body fat deposition. Several physiological differences in body composition are found in adolescence, and in girls in particular 20,21 ; however, the presence of a risk factor - fetal growth restriction - could have future health implications in terms of higher risk of metabolic syndrome and cardiovascular disease. ${ }^{6}$

Another interesting finding was the decreased upper arm muscle area in children born LBW, although the difference did not reach statistical significance. In a study of LBW infants, Sarni et al.22 found that these children were affected both by stunting and by lean mass loss, whereas Loos et al.23,24 found LBW to be associated with body composition in adulthood, with high body fat percentages and reduced lean mass. These authors suggest that fetal growth restriction in the third trimester, a period in which considerable weight gain normally occurs, could be a determining factor of changes in metabolism and muscle structure, which could, in turn, be associated with decreased lean mass percentages.

According to Kuh et al., ${ }^{25}$ lean mass loss secondary to fetal growth restriction has been associated with reduced muscle strength in adulthood. According to the authors, this damaging effect on muscle strength during intrauterine life is due to a reduction in the number of muscle fibers, which would be irreversible outside the womb and would actually be compounded by the inevitable lean mass loss of advancing age, with dire consequences on quality of life and independence in adulthood. 25 In the present study, lower lean mass percentages suggest that these children have trouble replenishing their protein stores, as muscle tissue mass is a reflection of body protein reserves. One might speculate that this finding provides further evidence of the repercussions of the perverse socioeconomic conditions to which these children are subjected.

One limitation of using body composition assessment indicators is the fact that these parameters are based on indirect measurements, obtained by mathematical means, and have low accuracy, as they regard the upper arm as a perfectly cylindrical structure with uniform fat distribution and thus underestimate adiposity. Furthermore, their use on a population-wide level is rather unfeasible. ${ }^{13}$

Motta et al. ${ }^{26}$ found that LBW infants are at increased odds of nutritional risk in the first year of life. This birth weight disadvantage was also reported by Eickmann et al., 27 at 2 years of age, in the present cohort. In this same population, Amorim et al. ${ }^{14}$ reported that, at 8 years of age, LBW had no influence on weight-for-age and height-forage, whereas maternal height and BMI and socioeconomic conditions played a major role in variation in these nutritional status indicators.
Analysis of the factors associated with TSF thickening showed that socioeconomic variables contributed most to TSF variation, which suggests a strong association between these variables and body composition at 8 years of age. The negative influence of maternal BMI $<25 \mathrm{~kg} / \mathrm{m}^{2}$ on TSF thickness could be considered both a proxy indicator of adverse socioeconomic and environmental conditions and a result of genetic inheritance, as mothers and their offspring share these same factors. ${ }^{28}$

Children with a history of fetal growth restriction are prone to infectious diseases in the first few months of life due to immune and nutritional deficits. ${ }^{2,3}$ However, at 8 years of age, unfavorable socioeconomic conditions are still present in the family environment, which may play a substantial role in worsening the nutritional status of this children during school age and, consequently, increasing morbidity. In this context of poverty, ignorance, low purchasing power, unhealthy and unsafe environmental conditions, and little access to health services, morbidity in this age range - represented in this study by anemia and hospitalization - also has a substantial negative effect on nutritional status.

In a study conducted in Africa, Delpeuch et al. ${ }^{29}$ found that the socioeconomic determinants of health can have a negative influence on child nutrition and that, as found in the present study, the combination of socioeconomic conditions and maternal characteristics is strongly associated with the nutritional status of the child. In a similar setting, Ulukanligil \& Seyrek ${ }^{30}$ found high prevalence rates of anemia, intestinal parasite infestation, and nutritional deficits in a sample of Turkish schoolchildren living in poor sanitation conditions - an environment comparable to that in which children in the southern Zona da Mata region of Pernambuco live.

In conclusion, our finding that socioeconomic factors and morbidity had a greater influence than LBW on TSF thickness in school-age children born full term may help health care providers and public health administrators gain a better understanding of the social reality of this region, providing them with a tool to guide short-, medium-, and long-term actions geared to reducing morbidity in these children and their families.

\section{References}

1. Kramer MS. The epidemiology of adverse pregnancy outcomes: an overview. J Nutr. 2003;133:1592S-6S.

2. Barros FC, Huttly SR, Victora CG, Kirkwood BR, Vaughan JP. Comparision of the causes and consequences of prematurity and intrauterine growth retardation: a longitudinal study in southern Brazil. Pediatrics. 1992;90:238-44.

3. Lira PI, Ashworth A, Morris SS. Low birth weight and morbidity from diarrhea and respiratory infection in northeast Brazil. J Pediatr. 1996;128:497-504. 
4. Branca F, Ferrari M. Impact of micronutrient deficiencies on growth: the stunting syndrome. Ann Nutr Metab. 2002;46 Suppl 1:8-17.

5. Rivera AJ, Hotz C, González-Cossío T, Neufeld L, García-Guerra A. The effect of micronutrient deficiencies on child growth: a review of results from community-based supplementation trials. J Nutr. 2003;133:4010S-20S.

6. Barker DJ. The developmental origins of adult disease. J Am Coll Nutr. 2004;23:588S-95S.

7. Gluckman PD, Hanson MA, Pinal C. The developmental origins of adult disease. Matern Child Nutr. 2005:1:130-41.

8. Meas T, Deghmoun S, Armoogum P, Alberti C, Levy-Marchal C. Consequences of being born small for gestational age on body composition: an 8-year follow-up study. J Clin Endocrinol Metab. 2008;93:3804-9.

9. Capurro H, Konichezky S, Fonseca D, Caldeyro-Barcia R. A simplified method for diagnosis of gestacional age in the newborn infant. J Pediatr. 1978;93:120-2.

10. World Health Organization (WHO). Physical Status: the use and interpretation of anthropometry. WHO Technical Report Series 854. Geneva; 1995.

11. Frisancho AR. Anthropometric standards for the assessment of growth and nutritional status. Ann Arbor: The University of Michigan Press; 1990.

12. World Health Organization (WHO). The Clinical use of Blood in Medicine, Obstetrics, Paediatrics, Surgery \& Anaesthesia, Trauma \& Burns. Geneva; 2001.

13. Gibson RS. Principles of Nutritional Assessment. 2nd ed. New York: Oxford University Press; 2005.

14. Amorim RJ, Lima MC, Lira PI, Emond AM. Does low birthweight influence the nutritional status of children at school age? a cohort study in northeast Brazil. Matern Child Nutr. Publicado on line: Feb 52010.

15. Malina RM, Katzmarzyk PT, Beunen G. Birth weight and its relationship to size attained and relative fat distribution at 7 to 12 years of age. Obes Res. 1996;4:385-90.

16. Hediger ML, Overpeck MD, Kuczmarski RJ, McGlynn A, Maurer KR, Davis WW. Muscularity and fatness of infants and young children born small- or large-for-gestational age. Pediatrics. $1998 ; 102 \mathrm{E} 60$.

17. Hack M, Schluchter M, Cartar L, Rahman M, Cuttler L, Borawski E. Growth of very low birth weight infants to age 20 years. Pediatrics. 2003;112:e30-8.

18. dos Anjos LA. Índices antropométricos e estado nutricional de escolares de baixa renda de um município do Estado do Rio de Janeiro (Brasil): um estudo piloto. Rev Saude Publica. 1989;23:221-9.

19. Monyeki KD, Kemper HC, Makgae PJ. Development and tracking of central patterns of subcutaneous fat of rural South African youth: Ellisras longitudinal study. BMC Pediatrics. 2009;9:74.
20. Barker M, Robinson S, Osmond C, Barker DJ. Birth weight and body fat distribution in adolescent girls. Arch Dis Child. 1997;77:381-3.

21. Santos EB, Amâncio OM, Oliva CA. Estado nutricional, ferro, cobre e zinco em escolares de favelas da cidade de São Paulo. Rev Assoc Med Bras. 2007;53:323-8.

22. Sarni RO, Souza FI, Pitta TS, Fernandez AP, Hix S, Fonseca FA. Baixo peso ao nascer: influência na pressão arterial, composição corporal e antropometria. Arq Med ABC. 2005;30:76-82.

23. Loos RJ, Beunen G, Fagard R, Derom C, Vlietinck R. Birth weight and body composition in young adult men-a prospective twin study. Int J Obes Relat Metab Disord. 2001;25:1537-45.

24. Loos RJ, Beunen G, Fagard R, Derom C, Vlietinck R. Birth weight and body composition in young women: a prospective twin study. Am J Clin Nutr. 2002;75:676-82.

25. Kuh D, Bassey J, Hardy R, Aihie Sayer A, Wadsworth M, Cooper C. Birth weight, childhood size, and muscle strength in adult life: evidence from a birth cohort study. Am J Epidemiol. 2002;156:627-33.

26. Motta ME, Silva GA, Araújo OC, Lira PI, Lima MC. O peso ao nascer influencia o estado nutricional ao final do primeiro ano de vida? J Pediatr (Rio J). 2005;81:377-82.

27. Eickmann SH, Lima MC, Motta ME, Romani AS, Lira PI. Crescimento de nascidos a termo com peso baixo e adequado nos dois primeiros anos de vida. Rev Saude Publica. 2006;40:1073-81.

28. Engstrom EM, Anjos LA. Déficit estatural nas crianças brasileiras: relação com condições sócio-ambientais e estado nutricional materno. Cad Saude Publica. 1999;15:559-67.

29. Delpeuch F, Traissac P, Martin-Prével Y, Massamba JP, Maire B. Economic crisis and malnutrition: socioeconomic determinants of anthropometric status of preschool children and their mothers in an African urban area. Public Health Nutr. 2000;3:39-47.

30. Ulukanligil M, Seyrek A. Anthropometric status, anaemia and intestinal helminthic infections in shantytown and apartment schoolchildren in the Sanliurfa province of Turkey. Eur J Clin Nutr. 2004;58:1056-61.

\section{Correspondence:}

Rosemary de Jesus Machado Amorim

Rua Xavier Marques, 209/1101 - Graças

CEP 52050-230 - Recife, PE - Brazil

Tel.: + 55 (81) 2126.8514

Fax: +55 (81) 2126.8514

E-mail: roseamorim@gmail.com 